\title{
High Performance Sine Wave Inverters Using Simulated Annealing Algorithm Tuned Non-Real-Valued Sliding Surface
}

\author{
En-Chih Chang, Chun-An Cheng, and Rong-Ching Wu
}

\begin{abstract}
In this paper, a simulated annealing algorithm tuned non-real-valued sliding surface is developed to enhance the transience and steady-state response of sine wave inverters. Even if the customary sliding surface (CSS) has the insensitivity to system uncertainties, the model of a reduced order exists in sliding action, thus yielding deficient system dynamics. By employing the non-real-valued sliding surface (NRVSS), the entire system dynamics can be established. Unfortunately, the occurrence of the chatter phenomenon is frequent and the harmonic distortion of sine wave inverter output is also high. To effectively reject the effect of the chatter, the NRVSS control gains can be optimally tuned via the simulated annealing algorithm (SAA). The proposed methodology has been implemented for the actual sine wave inverter controlled by a digital signal processor (DSP). Experimental results of the closed-loop system represent that the proposed methodology can provide fast transient response, low total harmonic distortion (THD) and the attenuation of steady-state error and chatter.
\end{abstract}

Index Terms-Non-real-valued sliding surface (NRVSS), chatter phenomenon, sine wave inverter, simulated annealing algorithm (SAA), total harmonic distortion (THD).

\section{INTRODUCTION}

Sine wave inverters have received more and more attention and are spaciously applied in energy conversion systems [1]-[4]. High-quality AC output voltage of low THD and fast dynamic response must be supplied by the sine wave inverter using feedback controller [5]-[7]. To finish these requirements, several control techniques have been reported, such as wavelet transform technique, mu-synthesis controller, deadbeat control, and repetitive control [8]-[11]. But, they are hard in realization and complicated in calculation. For the sake of more robust control systems, sliding mode control (SMC) can be adopted because of the insensitivity to system uncertainties [12-15]. The main SMC operation conception is to drive the system states toward a predetermined surface (reaching phase), i.e., the sliding surface or switching manifold defined in state space. In case the sliding surface is met, such a surface (sliding phase) will manage the system response and accordingly the strong robustness to the uncertainty or perturbation can be fulfilled [16]-[18]. The sliding mode controlled sine wave inverters have been provided in published literature [19], [20]. A single sliding-surface function is presented to perform the all control aims, but the transient and steady-state response are poor [21]. By employing the multi-loop control, the improved control method is proposed. However, nonzero steady-state error occurs [22]. A discrete SMC scheme with application to servo systems has been developed, and then this scheme is successfully used in PWM inverters. Fast transient response can be produced, but the distorted output-voltage is seen in the presence of nonlinear loading [23], [24]. The discrete feedforward sliding mode controlled inverter is presented and the transience and steady state are satisfactory. It is noteworthy that the chatterer exists around sliding surface [25]. A discrete integral SMC scheme is developed for uninterruptible power supply inverters. The chatter cannot be eliminated even if less steady-state error is obtained [26]. A combination of sliding and fuzzy control has been proposed for boost converters. There is good performance in transient behavior. However, the implementation of this approach is complex [27]. For the use of the boost regulators, the improved fuzzy sliding-mode is introduced to handle system uncertainties. Though this methodology has good steady-state response, the dynamic response is slow [28]. The sliding mode fuzzy logic controller is presented to get better transient and steady-state performance, but the chatter phenomenon still exists [29]. As above-these, as in sliding motion the customary sliding surface (CSS) yields reduced-order dimension, incurring deficient dynamics. To gain the entire system dynamics, the non-real-valued sliding surface (NRVSS) is introduced and then a whole dimension can be achieved [30], [31]. However, the chatter still appears around the NRVSS. The chatter may generate tear and wear to system components, leading to high harmonic distortion of sine wave inverter output. Simulated annealing algorithm (SAA) has been widely used in the fields of engineering [32]-[34] and is particularly suitable for solving difficult optimal problems [35]-[37]. The optimal control gains of the NRVSS can be tuned by SAA, thus diminishing the chatter. Finally, the proposed methodology is corroborated by the single-phase sine wave inverter, and is digitally realized using a digital signal processor. The efficacy and advantages of using the proposed methodology has been confirmed by experimental results.

\section{Proposed Methodology For Sine WAVE INVERTER}

\section{A. Modeling of Sine Wave Inverter}

Fig. 1 displays the block diagram of a sine wave inverter,
Manuscript received December 16, 2018; revised June 1, 2019.
The authors are with the Department of Electrical Engineering, I-Shou University, Kaohsiung City 84001, Taiwan (Corresponding Author e-mail: enchihchang@isu.edu.tw, cacheng@isu.edu.tw, rcwu@isu.edu.tw). 
followed by a LC filter. The full bridge inverter is the important core of the system, chopping the input of the direct current into a series of pulse width modulation pulses in accordance with the modulation signal. The second-order LC filter is capable of expelling high-frequency components of the chopped output-voltage $v_{i n}$. The direct current power source can be regarded as the supply of an ideal constant voltage. The load can be resistive load or step load change, or even nonlinear load.

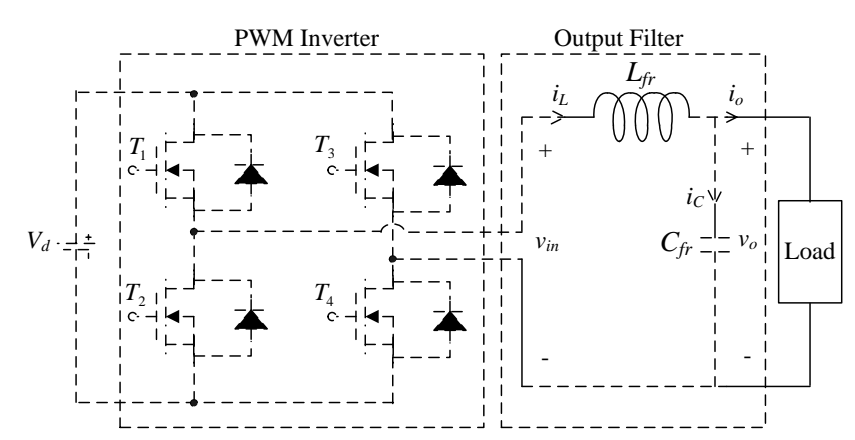

Fig. 1. Block diagram of sine wave inverter.

From the Fig. 1, the dynamic equation of the inverter with LC filter can be represented by

$$
\left[\begin{array}{c}
\dot{i}_{L} \\
\dot{v}_{O}
\end{array}\right]=\left[\begin{array}{cc}
0 & -\frac{1}{L_{f r}} \\
\frac{1}{C_{f r}} & 0
\end{array}\right]\left[\begin{array}{l}
\dot{v}_{O} \\
\dot{i}_{L}
\end{array}\right]+\left[\begin{array}{c}
\frac{1}{L} \\
0
\end{array}\right] v_{i n}+\left[\begin{array}{c}
0 \\
\dot{i}_{O} \\
C_{f r}
\end{array}\right]
$$

Suppose the switching frequency be high enough and the dynamics of the inverter can be regarded as a constant gain $K_{\text {pwm }}$. Hence, the linear model of sine wave inverter can be plotted in Fig. 2.

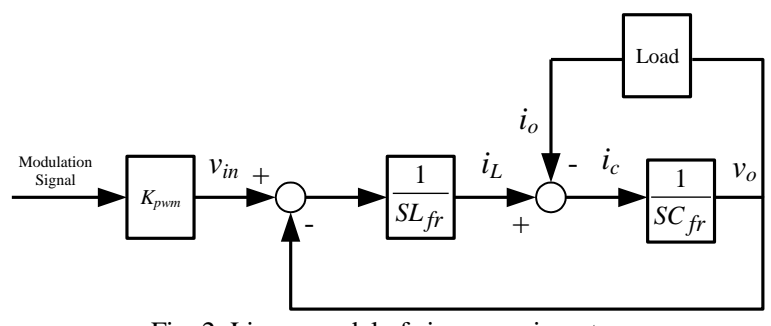

Fig. 2. Linear model of sine wave inverter.

Define the capacitor voltage $v_{O}$ and its derivative $\dot{v}_{O}$ as the state variables, the state equations can be written as

$$
\left[\begin{array}{l}
\dot{v}_{o} \\
\ddot{v}_{O}
\end{array}\right]=\left\lfloor\begin{array}{cc}
0 & 1 \\
-\frac{1}{L_{f r} C_{f r}} & 0
\end{array}\right\rfloor\left[\begin{array}{c}
v_{o} \\
\dot{v}_{O}
\end{array}\right]+\left\lfloor\frac{K_{p w m}}{L_{f r} C_{f r}}\right\rfloor u+\left\lfloor\begin{array}{c}
0 \\
-\frac{\dot{i}_{O}}{C_{f r}}
\end{array}\right\rfloor
$$

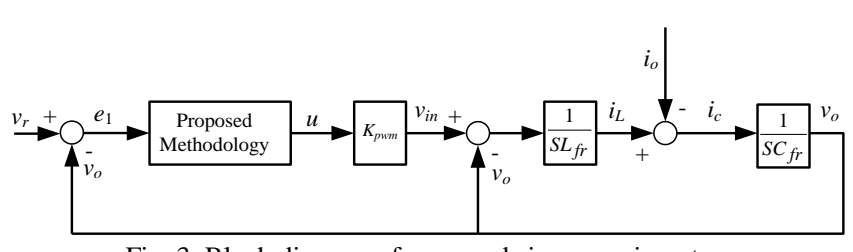

Fig. 3. Block diagram of proposed sine wave inverter.

Fig. 3 shows the block diagram of the proposed sine wave inverter. In order to assure a sinusoidal output-voltage, the capacitor voltage is sensed, thus governing the voltage-feedback loop.

Let $e_{1}=v_{r}-v_{o}$ and $e_{2}=\dot{e}_{1}$, we can obtain the error differential equations as follows:

$$
\left[\begin{array}{c}
\dot{e}_{1} \\
\dot{e}_{2}
\end{array}\right]=\left\lfloor-\frac{1}{L_{f r} C_{f r}} \quad 0 \mid\left[\begin{array}{c}
e_{1} \\
e_{2}
\end{array}\right]+\left\lfloor-\frac{K_{p w m}}{L_{f r} C_{f r}}\right\rfloor u+\left[\begin{array}{c}
0 \\
\Theta
\end{array}\right]\right.
$$

where $\Theta=\frac{1}{L_{f r} C_{f r}} v_{r}+\ddot{v}_{r}+\frac{\dot{i}_{O}}{C_{f r}}$ is the interference and $u$ stands for the control law.

\section{B. Customary Sliding Surface (CSS)}

The customary sliding surface can be chosen as

$$
\sigma=\operatorname{ker}(C) \subset \mathfrak{R}
$$

where $C \in \mathfrak{R}^{m \times n}$ and $\operatorname{rank}(C)=m$.

Then, the closed-loop dynamics can be established as

$$
\left[\begin{array}{c}
\dot{x} \\
\dot{y}
\end{array}\right]=\left[\begin{array}{cc}
\mathrm{R}_{\mathrm{e}} A & 0 \\
0 & \mathrm{R}_{\mathrm{e}} A
\end{array}\right]\left[\begin{array}{l}
x \\
y
\end{array}\right]+\left[\begin{array}{l}
0 \\
B
\end{array}\right] u
$$

where $A$ and $B$ are system matrix and control matrix, respectively.

As can be seen in (4) and (5), a $(n-m)$ reduced-order dimension yields and the performance of the system is therefore degraded. To gain the entire system dynamics, the NRVSS can be designed below.

\section{Non-Real-valued Sliding Surface (NRVSS)}

Assume that there are complex conjugate pairs $(v, \bar{v}$ and $z, \bar{z})$ in the following equations.

$$
\begin{aligned}
& u=0.5 \cdot(v+\bar{v}) \\
& x=0.5 \cdot(z+\bar{z})
\end{aligned}
$$

where $v, \bar{v} \in C^{m}$ and $z, \bar{z} \in C^{n}$

Substituting (6) and (7) into (5), the real model (5) becomes the sum of two complex models

$$
\begin{aligned}
& \dot{z}=A z+B v \\
& \overline{\dot{z}}=A \bar{z}+B v
\end{aligned}
$$

A non-real-valued sliding surface can be constructed as

$$
z=\left[\begin{array}{llllll}
x_{1} & \ldots & x_{m} & \dot{x}_{1} & \ldots & \dot{x}_{m}
\end{array}\right]^{T}
$$

where $\Omega \in C^{m \times n}$.

The sliding function matrix can be separated as

$$
\Omega=\left[\begin{array}{ll}
\Omega_{1} & \Omega_{2}
\end{array}\right]=\left(\begin{array}{ccccc}
M_{11}+i N_{11} & & 1 & & \\
& \ddots & & \ddots & \\
& & M_{m m}+i N_{m m} & & 1
\end{array}\right)
$$


where $\Omega_{1} \in C^{m \times(n-m)}$ and $\Omega_{2} \in C^{m \times m}$.

The system matrix can be derived as

$$
A_{z}=\left\lfloor\begin{array}{cc}
A_{11}-A_{12} \Omega_{2}^{-1} \Omega_{1} & A_{12} \\
0 & 0
\end{array}\right\rfloor
$$

Define $z=x+i y$ and then we can obtain following equations:

$$
\left\{\begin{aligned}
\overline{\dot{z}}+\dot{z} & =A_{z}(x+i y)+\bar{A}_{z}(x-i y) \\
& =2\left(\operatorname{Re} A_{z} x-\mathrm{I}_{\mathrm{m}} A_{z} y\right) \\
\overline{\dot{z}}-\dot{z} & =A_{z}(x+i y)+\bar{A}_{z}(x-i y) \\
& =2\left(\mathrm{I}_{\mathrm{m}} A_{z} x+\operatorname{Re} A_{z} y\right)
\end{aligned}\right.
$$

From (14), the $\mathfrak{R}^{2 n}$ dimensional model can be achieved as

$$
\left[\begin{array}{c}
\dot{x} \\
\dot{y}
\end{array}\right]=\left[\begin{array}{cc}
\mathrm{R}_{\mathrm{e}} A_{z} & -\mathrm{I}_{\mathrm{m}} A_{z} \\
\mathrm{I}_{\mathrm{m}} A_{z} & \mathrm{R}_{\mathrm{e}} A_{z}
\end{array}\right]\left[\begin{array}{l}
x \\
y
\end{array}\right]
$$

The control law can be formulated as

$$
\begin{aligned}
v= & \underbrace{-(\Omega B)^{-1} \Omega A z}_{u_{e z}} \\
& \underbrace{-(\Omega B)^{-1} \Omega A z\left[F \operatorname{sign}\left(\mathrm{R}_{\mathrm{e}}(\xi)+i G \operatorname{sign}\left(\mathrm{I}_{\mathrm{m}}(\xi)\right)\right]\right.}_{u_{s w z}}
\end{aligned}
$$

where $u_{e z}$ signifies the equivalent control and $u_{s w z}$ represents the sliding control.

In case $v=u+i w$, the (6) and (16) leads to

$$
\left\{\begin{array}{l}
u=-\mathrm{R}_{\mathrm{e}}(\Omega \mathrm{B})^{-1} \Omega A x+\mathrm{I}_{\mathrm{m}}(\Omega \mathrm{B})^{-1} \Omega A y \\
-\mathrm{R}_{\mathrm{e}}(\Omega \mathrm{B})^{-1} F \operatorname{sign}\left(\mathrm{R}_{\mathrm{e}} \xi\right)+\mathrm{I}_{\mathrm{m}}(\Omega \mathrm{B})^{-1} G \operatorname{sign}\left(\mathrm{I}_{\mathrm{m}} \xi\right) \\
w=-\mathrm{I}_{\mathrm{m}}(\Omega \mathrm{B})^{-1} \Omega A x+\mathrm{R}_{\mathrm{e}}(\Omega \mathrm{B})^{-1} \Omega A y \\
-\mathrm{I}_{\mathrm{m}}(\Omega \mathrm{B})^{-1} F \operatorname{sign}\left(\mathrm{R}_{\mathrm{e}} \xi\right)-\mathrm{R}_{\mathrm{e}}(\Omega \mathrm{B})^{-1} G \operatorname{sign}\left(\mathrm{I}_{\mathrm{m}} \xi\right)
\end{array}\right.
$$

Construct $\Omega=M+i N$, the (17) can be rewritten as

$$
\begin{aligned}
& {\left[\begin{array}{l}
u \\
w
\end{array}\right]=-\left[\begin{array}{ll}
\mathrm{R}_{\mathrm{e}}(\Omega B)^{-1} \Omega A & \mathrm{I}_{\mathrm{m}}(\Omega B)^{-1} \Omega A \\
\mathrm{I}_{\mathrm{m}}(\Omega B)^{-1} \Omega A & \mathrm{R}_{\mathrm{e}}(\Omega B)^{-1} \Omega A
\end{array}\right]\left[\begin{array}{l}
x \\
y
\end{array}\right]} \\
& +\left[\begin{array}{ll}
\mathrm{R}_{\mathrm{e}}(\Omega B)^{-1} F & \mathrm{I}_{\mathrm{m}}(\Omega B)^{-1} G \\
\mathrm{I}_{\mathrm{m}}(\Omega B)^{-1} F & \mathrm{R}_{\mathrm{e}}(\Omega B)^{-1} G
\end{array}\right] \cdot \operatorname{sign}\left(\left[\begin{array}{cc}
M & -N \\
N & M
\end{array}\right]\left[\begin{array}{l}
x \\
y
\end{array}\right]\right)
\end{aligned}
$$

By the use of the $y=0.5 \cdot(z-\bar{z})$, the differential equation can be obtained as

$$
\dot{y}=A y+B w
$$

Therefore, a $\mathfrak{R}^{2 n}$ dimensional model is produced and the dynamics deficient in the CSS design can be regained as follows:

$$
\left[\begin{array}{c}
\dot{x} \\
\dot{y}
\end{array}\right]=\left[\begin{array}{cc}
\mathrm{R}_{\mathrm{e}} A_{z} & -\mathrm{I}_{\mathrm{m}} A_{z} \\
\mathrm{I}_{\mathrm{m}} A_{z} & \mathrm{R}_{\mathrm{e}} A_{z}
\end{array}\right]\left[\begin{array}{l}
x \\
y
\end{array}\right]+\left[\begin{array}{cc}
B & 0 \\
0 & B
\end{array}\right]\left[\begin{array}{c}
u_{e z} \\
w_{s w z}
\end{array}\right]
$$

Eventually, $v=u_{e z}+i w_{s w z}$ is substituted for $u$. But, the chatter still exists in (16) and to effectively diminish the chatter, the SAA is employed to tune the control gains of the NRVSS. As the SAA is executed, a global minimum can be guaranteed to be reached with high probability. The artificial thermal noise is gradually reduced in time. A control parameter, i.e., computational temperature $T$ can handle the magnitude of the interferences of the energy function $E(x)$. Boltzmann distribution of the energy difference decides the probability of a state change as

$$
P=e^{-\Delta E / T}
$$

The process of the SAA is briefly described in the following and its flowchart is plotted in Fig. 4.

1) Initializing the system structure and then $x(0)$ is randomized.

2) Initializing $T$ with a large value.

3) Reiterate below:

a) Reiterate in the following

i) Applying random interferences to the state $x=x+\Delta x$.

ii) Evaluating $\Delta E(x)=E(x+\Delta x)-E(x)$ while $\Delta E<0$, and then maintain the new state or else agree to the new state with the probability $P=e^{-\Delta E / T}$; until the number of approved transitions is below a threshold level.

a) Arrange $T=T-\Delta T$, and until $T$ is small enough.

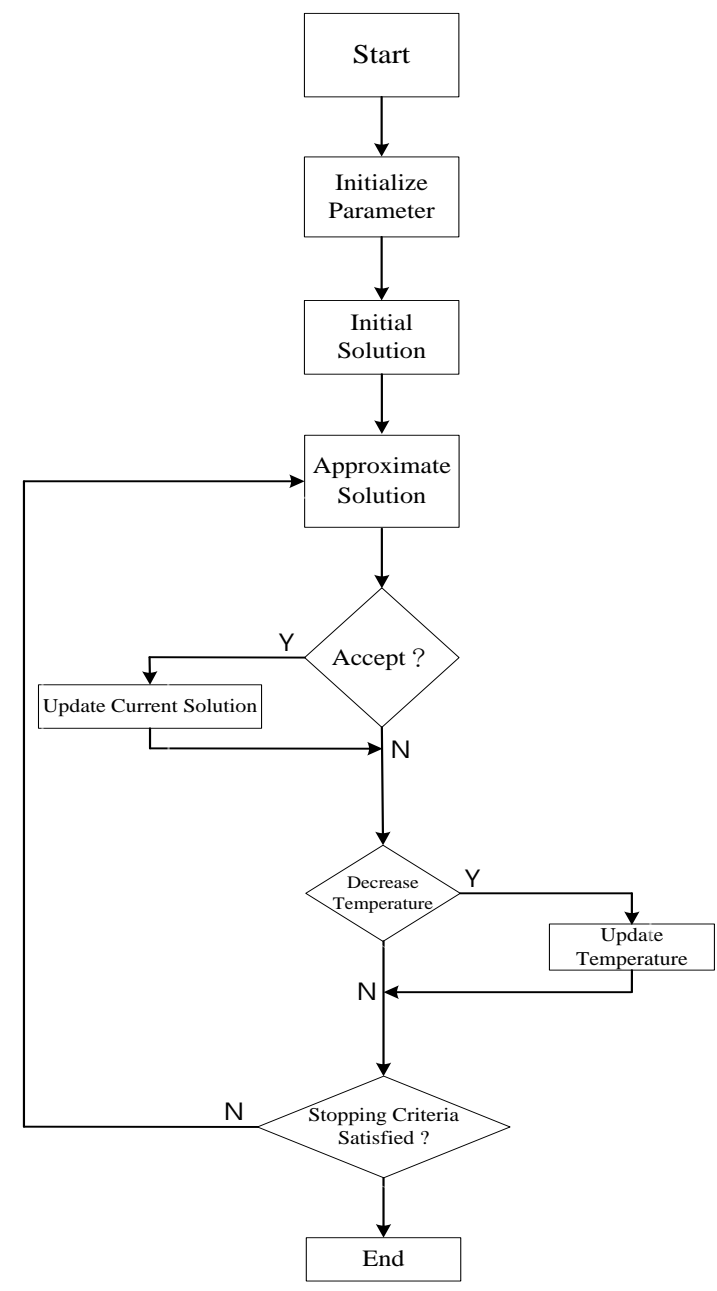

Fig. 4. Flowchart of the SAA. 


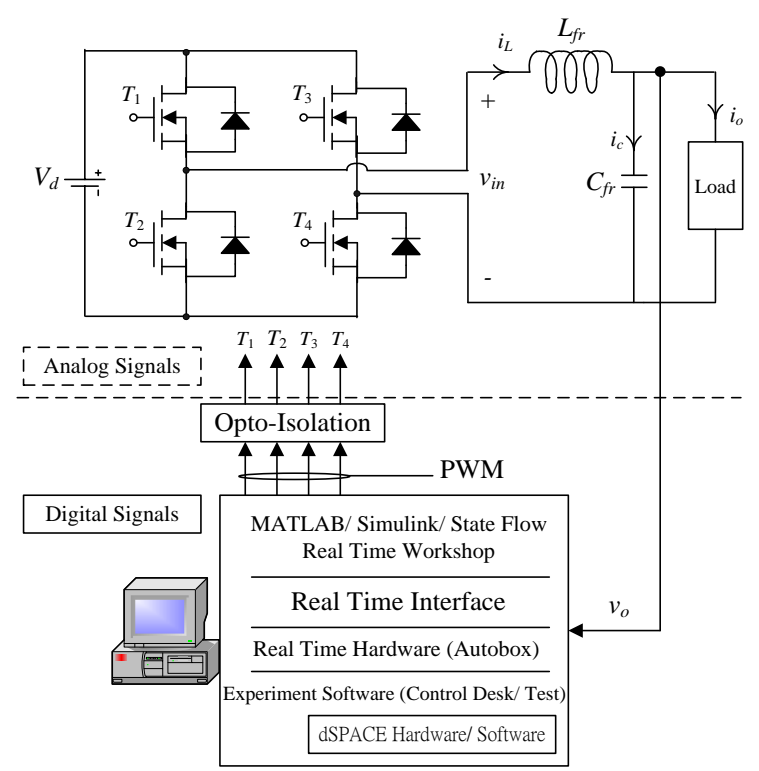

Fig. 5. Proposed sine wave inverter.

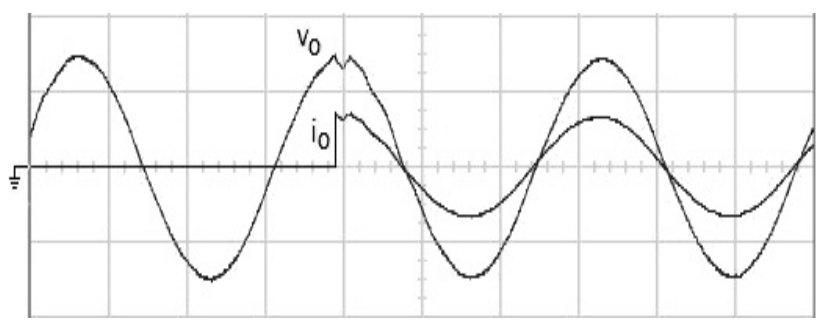

Fig. 6. Proposed methodology under step load change (vert.: 100 V/div; vert.: $20 \mathrm{~A} / \mathrm{div}$; hor. : $5 \mathrm{~ms} / \mathrm{div}$ ).

\section{EXPERIMENTAL RESULTS}

The proposed system parameters are given in Table I and the implemented structure of proposed sine wave inverter is also illustrated in Fig. 5. Fig. 6 illustrates the waveform obtained using the proposed methodology under the step load from no load to full load at a 90 degree firing angle. The satisfactory transience with small voltage dip can be observed and after the transience, the voltage waveform returns to high steady-state precision. Inversely, the waveform obtained using the customary sliding surface plotted in Fig. 7 has a large voltage dip and there is a slow recovery time. The values of filter parameters are assumed in suffering from 10\% $300 \%$ of nominal values while the sine wave inverter system is under $12 \Omega$ resistor. Fig. 8 and Fig. 9 display the output voltage waveform of the sine wave inverter controlled by the proposed methodology and the customary sliding surface, respectively. The proposed methodology has the insensitivity to the parameter variations and load interferences than the customary sliding surface. The proposed methodology is capable of producing a satisfactory steady-state and dynamic response, and displays notable improvement in reducing output-voltage distortion under filter parameter variations. Because the chatter is successfully diminished, Fig. 10 represents that the tracking error with the proposed methodology is rapidly converged to the origin. But, the customary sliding surface controlled sine wave inverter yields a large amount of tracking error, as shown in Fig. 11. Table II compares the voltage dip between the proposed methodology and customary sliding surface.
TABLE I: SYSTEM PARAMETERS

\begin{tabular}{|l|l|}
\hline \multicolumn{2}{|c|}{ TABLE I: SYSTEM PARAMETERS } \\
\hline DC-link voltage & $V_{d}=200 \mathrm{~V}$ \\
\hline Filter inductor & $L=0.2 \mathrm{mH}$ \\
\hline Filter capacitor & $C=4 \mu \mathrm{F}$ \\
\hline Resistive load & $R_{f u l l}=12 \Omega$ \\
\hline Output voltage and frequency & $v_{o}=110 \mathrm{~V}_{\mathrm{rms}}, f=60 \mathrm{~Hz}$ \\
\hline Switching frequency & $f_{s}=12 \mathrm{kHz}$ \\
\hline
\end{tabular}

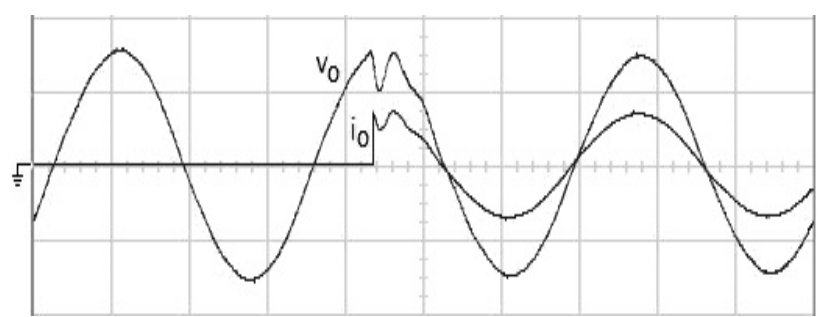

Fig. 7. Customary sliding surface under step load change (vert. : $100 \mathrm{~V} /$ div; vert. : $20 \mathrm{~A} / \mathrm{div}$; hor. : $5 \mathrm{~ms} / \mathrm{div})$.

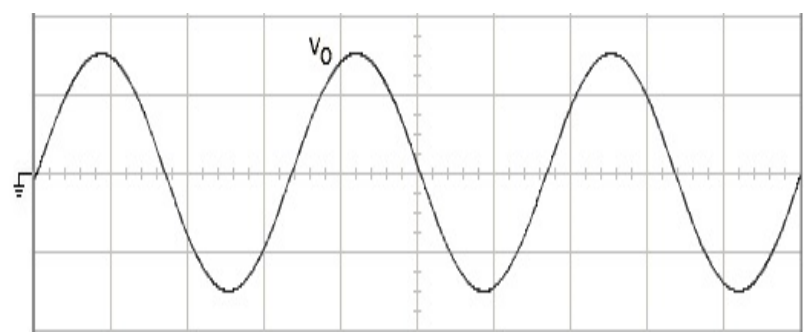

Fig. 8. Proposed methodology under LC parameter variations (vert.: 100 V/div; hor.: $5 \mathrm{~ms} / \mathrm{div}$ ).

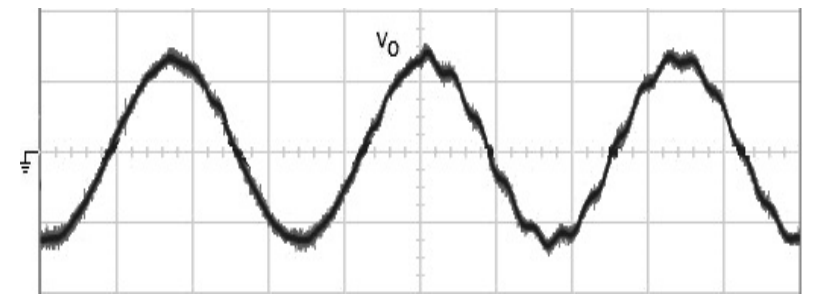

Fig. 9. Customary sliding surface under LC parameter variations (vert.: 100 V/div; hor.: $5 \mathrm{~ms} / \mathrm{div})$.

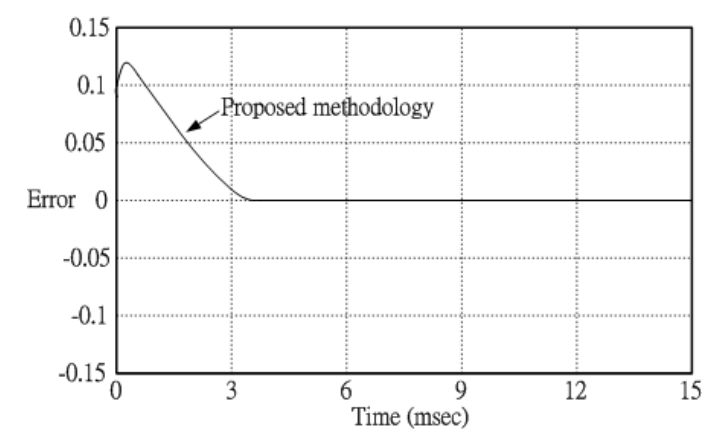

Fig. 10. Convergence speed of the proposed methodology.

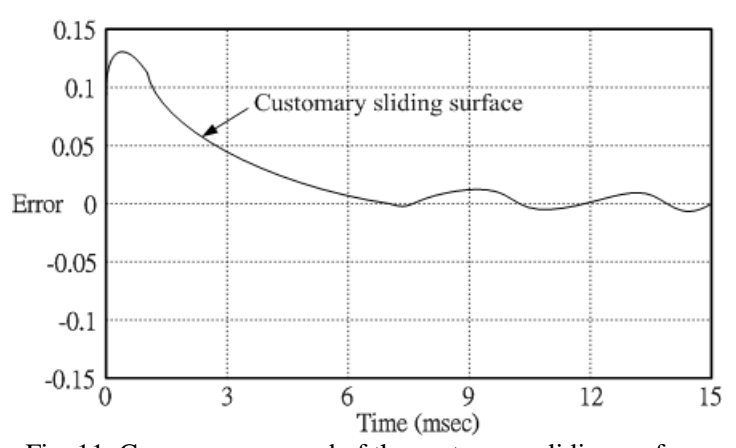

Fig. 11. Convergence speed of the customary sliding surface. 


\begin{tabular}{|c|c|}
\hline \multicolumn{2}{|c|}{ TABLE II: Voltage DIP } \\
\hline \multirow{2}{*}{ Experiment } & Proposed Methodology \\
\cline { 2 - 2 } & Voltage Dip \\
\cline { 2 - 2 } & Step Load Change \\
\hline \multirow{2}{*}{ Customary sliding surface } \\
\hline \multirow{2}{*}{ Experiment } & 22 $\mathrm{V}_{\mathrm{rms}}$ \\
\cline { 2 - 2 } & Soltage Dip \\
\cline { 2 - 2 } &
\end{tabular}

\section{CONCLUSIONS}

This paper presents a SAA-based NRVSS for the application of sine wave inverters. The customary SMC is intrinsically robust against internal parameter variations and external load interferences, but the problem of the deficient system model occurs. The NRVSS solves this problem, but the chatter still exists. By the use of the SAA, the NRVSS control gains can be tuned optimally, thus diminishing the chatter. Experimental results show that THD and transient response results from a sine wave inverter under the proposed system exceed the results achieved under the customary SMC system with both linear and nonlinear loading.

\section{ACKNOWLEDGMENT}

This work was supported by the Ministry of Science and Technology of Taiwan, R.O.C., under contract number MOST107-2221-E-214-006.

\section{REFERENCES}

[1] Simon, and O. Alejandro, Power-Switching Converters, CRC Press, Boca Raton, FL, USA, 2010.

[2] D. W. Hart, Power Electronics, McGraw-Hill, New York, NY, USA, 2010.

[3] B. M. Wilamowski and J. D. Irwin, Power Electronics and Motor Drives, CRC Press, Boca Raton, FL, USA, 2011.

[4] F. L. Luo and H. Ye, Power Electronics: Advanced Conversion Technologies, CRC Press, Boca Raton, FL, USA, 2010.

[5] R. Yuriy, R. Sergey, C. Evgeny, and V. Pavel, Power Electronics Basics: Operating Principles, Design, Formulas, and Applications, CRC Press, Boca Raton, FL, USA, 2016.

[6] L. D. Branko and B. Branko, Power Electronics: Converters and Regulators, Springer, New York, 2015.

[7] N. Mohan, T. M. Undeland, and W. P. Robbins, Power Electronics: Converters, Applications, and Design, Wiley, New York, USA, 2003.

[8] A. Pigazo, M. Liserre, R. A. Mastromauro, V. M. Moreno, and A. Dellaquila, "Wavelet-Based Islanding Detection in Grid-connected PV Systems," IEEE Transactions on Industrial Electronics, vol. 56, no. 11, pp. 4445-4455, 2009.

[9] T. S. Lee, K. S. Tzeng, and M. S. Chong, "Robust controller design for a single-phase UPS inverter using mu-synthesis," IEE Proc. Electr. Power Appl., vol. 151, no. 3, pp. 334-340, 2004.

[10] J. B. Hu and Z. Q. Zhu, "Improved voltage-vector sequences on dead-beat predictive direct power control of reversible three-phase grid-connected voltage-source converters," IEEE Transactions on Power Electronics, vol. 28, no. 1, pp. 254-267, 2013.

[11] D. Chen, J. M. Zhang, and Z. M. Qian, "An improved repetitive control scheme for grid-connected inverter with frequency-adaptive capability," IEEE Transactions on Industrial Electronics, vol. 60, no. 2, pp. 814-823, 2013.

[12] G. Bartolini, L. Fridman, A. Pisano, and E. Usai, Modern Sliding Mode Control Theory, Springer-Verlag, Berlin, 2008.

[13] L. G. Wu, P. Shi, and X. J. Su, Sliding Mode Control of Uncertain Parameter-Switching Hybrid Systems, Wiley, New York, 2014.

[14] S. Vaidyanathan and C. H. Lien, Applications of Sliding Mode Control in Science and Engineering, Springer, New York, 2017.
[15] V. I. Utkin, "Variable structure systems with sliding modes," IEEE Transactions on Automatic Control, vol. AC-22, no. 2, 1977, pp. 212-222.

[16] H. Sira-Ramirez, "Sliding regimes in general non-linear systems: A relative degree approach," Int. J. Contr., vol. 50, no. 4, pp. 1487-1506, 1989.

[17] Z. Doulgeri, "Sliding regime of a nonlinear robust controller for robot manipulators," IEE Proceedings-Control Theory and Applications, vol. 146, no. 6, pp. 493-498, 1999.

[18] S. P. Stanchev, "A variant of an (combined) adaptive controller design introducing sliding regime in Lyapunov derivative," in Proc. Int. Conf. American Control Conference, 2003, pp. 909-914.

[19] A. T. Azar, and Q. M. Zhu, Advances and Applications in Sliding Mode Control Systems, Springer, New York, 2015.

[20] S. C. Tan, Y. M. Lai, and C. K. Tse, Sliding Mode Control of Switching Power Converters: Techniques and Implementation, CRC Press, Boca Raton, FL, USA, 2012.

[21] K. Jezernik and D. Zadravec, "Sliding mode controller for a single phase inverter," in Proc. IEEE APEC'90, 1990, pp. 185-190.

[22] S. J. Chiang, T. S. Tai, and T. S. Lee, "Variable structure control of UPS inverters," in Proc. IEE-Elect. Power Applicat., 1998, vol. 145, no. 6, pp. 559-567.

[23] C. Y. Chan, "Servo-system with discrete-variable structure control," Syst. Contr. Lett., vol. 17, no. 4, pp. 321-325, 1991.

[24] S. L. Jung, Y. Y. Tzou, "Sliding mode control of a closed-loop regulated PWM inverter under large variations," in Proc. IEEE PESC'93, 1993, pp. 616-622.

[25] S. L. Jung and Y. Y. Tzou, "Discrete feedforward sliding mode control of a PWM inverter for sinusoidal output waveform synthesis," in Proc. IEEE PESC'94, 1994, pp. 552-559.

[26] T. L. Chern, J. Chang, C. H. Chen, and H. T. Su, "Microprocessor-based modified integral discrete variable-structure control for UPS," IEEE Trans. Ind. Electron., vol. 46, pp. 340-348, 1999.

[27] E. Vidal-Ldiarte, L. Martinez-Salamero, F. Guinjoan, J. Calvente, and S. Gomariz, "Sliding and fuzzy control of a boost converter using an 8-bit microcontroller," in Proc. IEE-Elect. Power Applicat., 2004, vol. 151, no. 1, pp. 5-11.

[28] S. Gomariz, E. Alarcon, F. Guinjoan, E. Vidal-ldiarte, and L. Martinez-Salamero, "Piecewise PWM-sliding global control of a boost switching regulator by means of first-order Takagi-Sugeno fuzzy control," in Proc. Conf. IEEE Circuits Syst., 2001, vol. 3, pp. 715-718.

[29] Y. Shi and P. C. Sen, "Application of variable structure fuzzy logic controller for DC-DC converters," in Proc. Conf. IEEE IECON'01, 2001, vol. 1, pp. 2026-2031.

[30] B. M. Shepit and J. K. Pieper, "Sliding mode control design for complex valued sliding manifold," in Proc. Conf. IEEE Decision and Contr., 2001, vol. 1, pp. 920-921.

[31] B. M. Shepit and J. K. Pieper, "Sliding-mode control design for a complex valued sliding manifold," IEEE Trans. Autom. Contr., vol. 48, no. 1, pp. 122-127, 2003.

[32] P. J. van Laarhoven, and E. H. Aarts, Simulated Annealing: Theory and Applications, Springer, Netherlands, 1987.

[33] S. Kirkpatrick, C. D. Gelatt, and M. P. Vecchi, "Optimization by simulated annealing," Science, vol. 220, pp. 671-680, 1983.

[34] X. Yao, "A New simulated annealing algorithm," International Journal of Computer Mathematics., vol. 56, no. 3-4, pp. 161-168, 1995.

[35] V. Fabian, "Simulated annealing simulated," Computers \& Mathematics with Applications., vol. 33, no. 1-2, pp. 81-94, 1997.

[36] J. Haddock, and J. Mittenthal, "Simulation optimization using simulated annealing", Computers \& Industrial Engineering, vol. 22, no. 4, pp. 387-395, 1992.

[37] K. L. Du and M. N. S. Swamy, Search and Optimization by Metaheuristics, Springer, Switzerland, 2016.

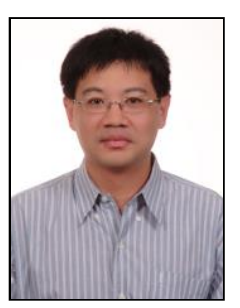

En-Chih Chang was born in Kaohsiung, Taiwan, in 1975. He received his B.S. degree from Feng-Chia University, Taichung, Taiwan in 1999; his M.S. degree from the National Taiwan Ocean University, Keelung, Taiwan in 2001; and his Ph.D. degree from the National Cheng Kung University, Tainan, Taiwan in 2008, all in electrical engineering. He is presently working as an associate professor in the Department of Electrical Engineering, I-Shou University, Kaohsiung, Taiwan, ROC. His current research interests include sliding mode control, intelligent control, grey 
theory, and their applications in power electronics systems.

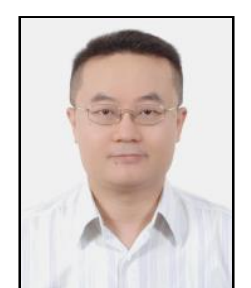

Chun-An Cheng was born in Kaohsiung, Taiwan, in 1974. He received the B.S. degree in electrical engineering from the National Taipei University of Technology, Taipei, Taiwan in 1998, and the Ph.D. degree in electrical engineering from the National Cheng Kung University, Tainan, Taiwan in 2006.

Since August 2006, he has been with the Faculty of the Department of Electrical Engineering, I-Shou University, Kaohsiung, Taiwan, where he is currently a professor. In May 2011, he received excellent electrical engineer award from the Chinese Institute of Electrical Engineering (CIEE) Kaohsiung region. His main research interests include power electronics, converters, inverters and electronic ballasts/drivers for lighting applications.

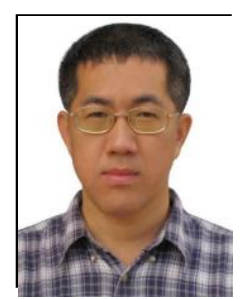

Rong-Ching Wu graduated from National Taiwan Institute of Technology, Taipei, Taiwan, in 1990. He received the M.Sc. degree in 1994 and received the Ph.D. degree in 2001 from National Sun Yat-Sen University, Kaohsiung, Taiwan. From 1991 to 2001, he was an Electrical Engineer in Taiwan Power Company, Kaohsiung, Taiwan, and was involved with design, construction, and operation of power systems. Currently, he is an associate professor at I-Shou University, Kaohsiung, Taiwan. 